\title{
CYP1A2 genotype and acute effects of caffeine on resistance exercise, jumping, and sprinting performance
}

\author{
Jozo Grgic ${ }^{1 *}$, Craig Pickering ${ }^{2}$, David J. Bishop ${ }^{1,3}$, Brad J. Schoenfeld $^{4}$, Pavle Mikulic $^{5}$ and Zeljko Pedisic ${ }^{1}$
}

\begin{abstract}
Background: It has been suggested that polymorphisms within CYP1A2 impact inter-individual variation in the response to caffeine. The purpose of this study was to explore the acute effects of caffeine on resistance exercise, jumping, and sprinting performance in a sample of resistance-trained men, and to examine the influence of genetic variation of CYP1A2 (rs762551) on the individual variation in responses to caffeine ingestion.
\end{abstract}

Methods: Twenty-two men were included as participants (AA homozygotes $n=13$; C-allele carriers $n=9$ ) and were tested after the ingestion of caffeine ( $3 \mathrm{mg} / \mathrm{kg}$ of body mass) and a placebo. Exercise performance was assessed with the following outcomes: (a) movement velocity and power output in the bench press exercise with loads of $25,50,75$, and $90 \%$ of one-repetition maximum (1RM); (b) quality and quantity of performed repetitions in the bench press exercise performed to muscular failure with 85\% 1RM; (c) vertical jump height in a countermovement jump test; and (d) power output in a Wingate test.

Results: Compared to placebo, caffeine ingestion enhanced: (a) movement velocity and power output across all loads (effect size [ES]: $0.20-0.61 ; p<0.05$ for all); (b) the quality and quantity of performed repetitions with $85 \%$ of 1 RM (ES: $0.27-0.85 ; p<0.001$ for all); (c) vertical jump height (ES: 0.15; $p=0.017$ ); and (d) power output in the Wingate test (ES: $0.33-0.44 ; p<0.05$ for all). We did not find a significant genotype $\times$ caffeine interaction effect ( $p$ values ranged from 0.094 to 0.994 ) in any of the analyzed performance outcomes.

Conclusions: Resistance-trained men may experience acute improvements in resistance exercise, jumping, and sprinting performance following the ingestion of caffeine. The comparisons of the effects of caffeine on exercise performance between individuals with the AA genotype and AC/CC genotypes found no significant differences.

Trial registration: Australian New Zealand Clinical Trials Registry. ID: ACTRN12619000885190.

Keywords: Supplements, Ergogenic effects, Genetic, Variation

\section{Background}

Caffeine is one of the most consumed psychoactive stimulants in the world [1]. The effects of caffeine supplementation on exercise performance have received considerable attention in the literature, and the evidence on its ergogenic effects is well-established [1-3]. For

\footnotetext{
* Correspondence: jozo.grgic@live.vu.edu.au

${ }^{1}$ Institute for Health and Sport (IHES), Victoria University, Melbourne, Australia Full list of author information is available at the end of the article
}

example, a recent umbrella review of 21 published metaanalyses reported that caffeine ingestion is acutely ergogenic for aerobic endurance, muscle strength, muscle endurance, power, jumping performance, and exercise speed [3]. Despite these established performanceenhancing effects of caffeine, it is also commonly acknowledged that there is a large degree of variation in response to caffeine supplementation between individuals [4]. Studies that have reported individual participant

C C The Author(s). 2020 Open Access This article is licensed under a Creative Commons Attribution 4.0 International License, which permits use, sharing, adaptation, distribution and reproduction in any medium or format, as long as you give appropriate credit to the original author(s) and the source, provide a link to the Creative Commons licence, and indicate if changes were made. The images or other third party material in this article are included in the article's Creative Commons licence, unless indicated otherwise in a credit line to the material. If material is not included in the article's Creative Commons licence and your intended use is not permitted by statutory regulation or exceeds the permitted use, you will need to obtain permission directly from the copyright holder. To view a copy of this licence, visit http://creativecommons.org/licenses/by/4.0/. The Creative Commons Public Domain Dedication waiver (http://creativecommons.org/publicdomain/zero/1.0/) applies to the data made available in this article, unless otherwise stated in a credit line to the data. 
data suggest that some individuals experience an increase in performance following caffeine ingestion, whereas others do not [4-6]. In order to develop more effective guidelines for caffeine supplementation in sport and exercise settings, the scientific focus has recently been placed on examining and understanding the reasons for the between-individual variation in responses $[4,7]$.

One potential driver of this individual response is inter-individual genetic variation [4]. The gene CYP1A2 encodes cytochrome P450 1A2, an enzyme responsible for up to $95 \%$ of caffeine metabolism [8]. The speed of caffeine metabolism is affected by a single nucleotide polymorphism, rs762551, within this gene [8]. Individuals with the AA genotype at rs762551 are commonly classified as "fast caffeine metabolizers", while $\mathrm{C}$ allele carriers (AC/CC genotypes) tend to have a slower clearance of caffeine and are, therefore, commonly classified as "slow caffeine metabolizers" [9]. Significantly greater ergogenic effects of caffeine on aerobic endurance have been reported for individuals with the AA genotype, compared with $\mathrm{C}$ allele carriers $[6,10]$. However, for high-intensity exercise tasks of a shorter duration, the evidence is less clear.

In a recent study of 19 basketball players, acute ingestion of $3 \mathrm{mg} / \mathrm{kg}$ of caffeine produced similar effects on vertical jump performance in individuals with the AA genotype and AC/CC genotypes [11]. These results are in accord with a study that utilized a 30-s Wingate sprint test, while improvement in peak and mean power output was noted following caffeine ingestion, the researchers did not find differences in responses between genotypes [12]. Based on the results of these two studies, it seems variations in the CYP1A2 genotype may not affect the ergogenic effects of caffeine ingestion on high-intensity exercise performance. However, a recent study reported that caffeine ingestion enhances the number of performed repetitions in a resistance exercise session in individuals with the AA genotype but not AC/CC genotypes [13].

Given the conflicting evidence on this topic, the aim of this randomized, double-blind crossover study was to explore the acute effects of caffeine on resistance exercise, jumping, and cycle ergometer sprint performance in a sample of resistance-trained men and the influence of genetic variation of CYP1A2 (rs762551) on the individual variation in responses. We hypothesized that caffeine ingestion would be ergogenic across all exercise tasks and that individuals with the AA genotype would experience greater improvements in exercise performance following caffeine ingestion than those with $\mathrm{AC} / \mathrm{CC}$ genotypes.

\section{Methods}

\section{Experimental design}

This study employed a double-blind, randomized, crossover design. All participants attended four laboratory sessions. All trials were performed in the morning hours (between $7 \mathrm{am}$ and noon), and at the same time of the day across the sessions for each participant, to ensure that the results were not affected by circadian variation [14]. The trials took place 4 to 7 days apart. The first and second session included familiarization with the exercise protocol (explained in detail in the "Exercise protocol" section). The two main sessions (i.e., caffeine and placebo sessions) were conducted in a randomized and counterbalanced order. The participants were randomly assigned to the two conditions; half of the participants ingested caffeine in the first session and a placebo in the second session, while the other half ingested a placebo in the first session and caffeine in the second session. Participants were asked not to perform any strenuous exercise for at least 24 hours before the main trials. The participants were also asked to keep a food diary for $24 \mathrm{~h}$ using "MyFitnessPal" software, and to match their dietary intakes on the days before the two main sessions as much as possible. The participants were required to refrain from caffeine intake after $6 \mathrm{pm}$ on the day prior to the testing [1]. In order to assist with caffeine restriction, we provided the participants with a list of the most common foods and drinks that contain caffeine. The participants arrived at the laboratory following overnight fasting. Caffeine was administered in capsule form, with a dose of $3 \mathrm{mg} / \mathrm{kg}$ of body mass (equivalent to the caffeine dose contained in approximately two cups of coffee). The placebo capsule was identical in appearance to the caffeine capsule, but, instead of caffeine, it contained $3 \mathrm{mg} / \mathrm{kg}$ of dextrose. The capsules were ingested $60 \mathrm{~min}$ before the start of the exercise session [1]. Genotype was determined using a buccal swab. A validated Food Frequency Questionnaire was used to estimate habitual caffeine intake [15]. Prior to the study, the trial was registered in the Australian New Zealand Clinical Trials Registry ID: ACTRN12619000885190.

\section{Participants}

The study involved resistance-trained men as participants. Being resistance-trained was defined in this study as having a minimum of 6 months of resistance training experience with a minimum weekly training frequency of two times on most weeks. All participants were nonsmokers. Based on an a priori power analysis done using G*Power software (version 3.1; Germany, Dusseldorf) for repeated-measures Analysis of Variance (ANOVA) (within-between interaction, i.e., in the context of this study genotype $\times$ caffeine interaction), with an assumed true effect size $f$ of 0.25 , the alpha error level of 0.05 , 
and the expected correlation between repeated measures of 0.75 , the required sample size to achieve the statistical power of $80 \%$ for this study was 18 participants. To factor in possible dropouts, we recruited 22 participants. The exclusion criteria were: (i) prior use of anabolic steroids; and (ii) the existence of any health limitations. Ethical approval for this study was granted by the Victoria University Human Research Ethics Committee (HRE19-019). The remaining data of the project are published elsewhere [16]. Before enrolling in the study, every participant signed an informed consent and filled out a Physical Activity Readiness Questionnaire (PARQ). Only participants who responded with 'No' to all PAR-Q items were included in the study. In line with previous research $[6,11-13]$, we combined participants with the $\mathrm{AC}$ and $\mathrm{CC}$ genotypes into one group (AC/CC group) for the analysis.

\section{Exercise protocol}

One repetition maximum testing The first two sessions included familiarization with the exercise protocol. These sessions were the same as the main sessions (i.e., placebo and caffeine sessions), with the exception that the first one included one-repetition maximum (1RM) testing in the bench press exercise. For the 1RM test, the participants performed sets of one repetition with progressive increases in load until they reached their estimated $1 \mathrm{RM}$. The load was initially set to $20 \mathrm{~kg}$ and subsequently increased by $10 \mathrm{~kg}$ increments if the mean concentric velocity of the repetition was $0.4 \mathrm{~m} / \mathrm{s}$ or higher (as determined by a linear position transducer attached to the barbell). If the mean velocity was lower than $0.4 \mathrm{~m} / \mathrm{s}$, the load for the next attempt was adjusted using smaller increases (e.g., $5 \mathrm{~kg}$ or $2.5 \mathrm{~kg}$, determined based on consultation with the participants). The participants performed 1RM attempts with progressively increasing loads until the mean velocity was $\leq 0.2 \mathrm{~m} / \mathrm{s}$ [17]. When the mean velocity of a successful 1RM attempt reached these values, the load was considered as a valid estimate of the 1RM [17]. Three minutes were allowed between 1RM attempts.

Movement velocity and power in the bench press exercise In the first session, upon determining the 1RM, the participants performed the bench press exercise with loads of $25,50,75$, and $90 \%$ of 1RM [18]. The second, third, and fourth sessions started with the assessment of movement velocity in the bench press exercise with different loads, as the 1RM test was only performed in the first session. The external load was first set at $25 \%$ of $1 \mathrm{RM}$ and was progressively increased to $90 \%$ of $1 \mathrm{RM}$. With each load, the participants performed two sets of one repetition and were instructed to lift the load as fast as possible. The better repetition (in the context of higher movement velocity and power output) was used for the analysis. Each repetition was followed by a 3-min rest interval. During each repetition, a GymAware linear position transducer (GymAware Power Tool, Kinetic Performance Technologies, Canberra, Australia) was attached to the barbell and used to measure mean concentric velocity $(\mathrm{m} / \mathrm{s})$, mean power $(\mathrm{W})$, peak concentric velocity $(\mathrm{m} / \mathrm{s})$, and peak power $(\mathrm{W})$. Previous research has established that this device has good test-retest reliability for power and velocity outcomes in the bench press [19].

Muscle endurance After the final repetition with 90\% of 1RM, participants were provided with $5 \mathrm{~min}$ of passive rest. After the rest interval, muscle endurance was assessed with a test that involved performing repetitions to momentary muscle failure with a load corresponding to $85 \%$ of $1 \mathrm{RM}$ in the bench press exercise, as in the study by Rahimi [13]. Besides the total number of repetitions, we also measured velocity and power output for each repetition using the linear position transducer attached to the barbell. For the purpose of statistical analyses, we compared the total number of repetitions in the placebo and caffeine conditions. We also explored movement velocity and power output of all repetitions by matching the number of repetitions between the placebo and caffeine conditions. For example, if a participant performed eight repetitions following the ingestion of placebo and nine following the ingestion of caffeine, for this part of the analysis, we only considered movement velocity and power output in the first eight repetitions. This approach allowed us to objectively quantify the average quality of the repetitions during the test and examine if caffeine ingestion had an effect on movement velocity and power output when the total number of repetitions was matched.

Countermovement jump After the muscle endurance test, participants rested passively for 3 minutes and then performed 1 minute of light running, followed by 10 bodyweight squats, in order to warm-up for the countermovement jump (CMJ). The participants performed a $\mathrm{CMJ}$ on a force platform (400S Isotronic Fitness Technology, Skye, South Australia, Australia). The CMJ was performed without an arm swing. The participants started CMJ testing from an upright standing position on the force platform. The participants positioned themselves in the starting position and then received commands from the software displayed on a computer screen that was in front of the platform. The software counted down, "3, 2, 1" and provided "Set" and "Go" commands. After the "Go" command, the participants had 5 seconds to complete the jump. From the starting 
position, the participants performed a downward countermovement (i.e., a fast knee flexion) where their lowest position was a semi-squat position (knee $\sim 90^{\circ}$ and trunk/hips in a flexed position) [20]. Immediately after reaching this point, the participants performed an "explosive" extension of the legs [20]. The participants were given instructions to jump as quickly and "explosively" as possible to achieve maximal vertical jump height [20]. The participants had one warm-up jump and three official attempts. Each attempt was followed by 1 minute of rest. For the analysis, the best jump from three official attempts was used. The outcome in the CMJ test was vertical jump height, determined by an algorithm based on the flight time.

Wingate test After the $\mathrm{CMJ}$ test, the participants were provided another 3 minutes of passive rest before starting the Wingate test. The Wingate test was performed using a Lode Excalibur Sport Cycle Ergometer (The Netherlands, Groningen). Individual setup of the cycle ergometer; namely, saddle and handlebar height and length, was determined in the first session and was maintained throughout all subsequent trials. The Wingate test started with a 5-min warm-up $(100 \mathrm{~W}$ at $60-$ $80 \mathrm{rpm}$ ) [21]. After the warm-up, participants performed a 30-s "all-out" sprint while the resistance placed on the flywheel remained constant at $0.75 \mathrm{Nm} / \mathrm{kg}$. The participants remained seated during the 30-s sprint. During the test, peak power, mean power, and minimum power were recorded using the Lode Ergometry Manager 10 software. Peak power was defined as the greatest power value recorded during the $30-\mathrm{s}$; mean power was the arithmetic mean of power during the test, and minimum power was the lowest power recorded during the sprint.

\section{Side effects}

Side effects of caffeine and placebo supplementation were evaluated at two time points: (1) immediately after the completion of the testing sessions; and (2) in the following mornings, upon waking. The participants responded to an 8-item survey regarding the incidence of side effects ("yes/no" response scale). This survey was also used to examine side effects in previous research that explored effects of caffeine on exercise performance $[20,22,23]$.

\section{Assessment of blinding}

Both in the caffeine and the placebo trials, before and after the exercise session, participants responded to the following question: "Which supplement do you think you have ingested?" [24]. The question had three possible responses: (a) "caffeine", (b) "placebo" and (c) "I do not know" [24]. In case participants respond with "a" or "b", they were required to state the reason for choosing their response.

\section{Genetic testing}

The participants underwent genetic testing using a commercially available testing kit from DNAfit Life Sciences (London, UK), as in other studies [25]. Samples were collected using buccal swab devices, with OCR-100 kits by DNAGenotek (Ottawa, Canada). The participants were required to avoiding eating or drinking for at least $60 \mathrm{~min}$ prior to the sample collection. All samples were collected according to the manufacturer guidelines. The samples were sent to IDna Genetics Laboratory (Norwich, UK), where the analysis was performed. DNA was extracted and purified using the Isohelix Buccalyse DNA extraction kit BEK-50 (Cell Projects Ltd., Kent, UK), and amplified through polymerase chain reaction (PCR) on an ABI 7900 real-time thermocycler (Applied Biosystem, Waltham, USA). The samples were analyzed for the CYP1A2 rs762551 single-nucleotide polymorphism. This analysis was performed after the exercise performance data collection; thus, the researchers and participants were blinded to genotype variations of the cohort until the data collection process was finalized.

\section{Statistical analysis}

One-way ANOVA was used to test the differences between genotype groups in age, body mass, height, 1RM, and habitual caffeine intake. We used a two-way, repeated-measures ANOVA to test genotype (AA genotype vs. AC/CC genotypes) $\times$ caffeine (placebo vs. caffeine) interaction effect on performance data, separately for each performance variable. In the absence of significant genotype $\times$ caffeine interaction effects, we conducted no stratified analyses of the effects of caffeine by genotype groups. Relative effect sizes (ES) were calculated as Hedge's $g$ for repeated measures and presented together with their respective $95 \%$ confidence intervals (95\% CIs). ESs of $<0.20,0.20$ to $0.49,0.50$ to 0.79 , and $\geq$ 0.80 were considered to represent trivial, small, moderate, and large effects, respectively. McNemar's test was used in the comparison of the incidence of side effects between the placebo and caffeine conditions. The blinding data were summarized using the Bang's Blinding Index [26]. The values in this index range from -1.0 (denoting opposite guessing) to 1.0 (denoting complete unblinding) [26]. For this study, we reported the data from this index as a percentage of individuals who identified the correct treatment condition beyond chance $[19,26]$. All analyses were performed using the Statistica software (version 13.4.0.14; TIBCO Software Inc., Palo Alto, CA, USA). The significance level was set at $p<0.05$. 


\section{Results}

\section{Study participants}

All participants completed all testing procedures and were included in the final analysis. Of the whole sample, 13, 7, and 2 participants were categorized as having the AA, AC, or CC genotype, respectively. The participants' characteristics are presented in Table 1. There were no significant differences between the genotype groups for age, body mass, height, 1RM, or habitual caffeine intake.

\section{Movement velocity and power output in the bench press exercise}

We did not find a significant main effect for genotype $(p>0.05$ for all) or a genotype $\times$ caffeine interaction effect for any of the 16 analyzed variables for movement velocity and power output in the bench press exercise (mean power, mean velocity, peak power, and peak velocity at 25, 50, 75, and 90\% 1RM; Table 2). For all variables, except peak power output at 50\% 1RM, there was a significant main effect favoring caffeine $(p<0.05)$. The ESs, favoring caffeine conditions in all outcomes, ranged from 0.20 to 0.29 for all outcomes recorded at $25 \%$ $1 \mathrm{RM}$, from 0.21 to 0.23 for all outcomes at 50\% 1RM, from 0.31 to 0.50 for all outcomes at 75\% 1RM, and from 0.57 to 0.61 for outcomes at 90\% 1RM.

\section{Muscle endurance}

For the maximum number of repetitions in the bench press exercise with $85 \% 1 \mathrm{RM}$, we did not find a significant main effect for genotype $(p=0.397)$ or a genotype $\times$ caffeine interaction effect $(p=0.454)$, while there was a significant main effect favoring caffeine $(p<0.001$; ES $=$ 0.53 ). For peak velocity, mean power output, and peak power output (matched for repetitions between placebo and caffeine conditions), we did not find a significant main effect for genotype ( $p>0.05$ for all) or a genotype $\times$ caffeine interaction effect $(p>0.05$ for all), while there was a significant main effect favoring caffeine in all three variables $(p<0.001$ for all). The ESs ranged from 0.27 to 0.53 . For mean velocity, there was a significant main effect for genotype $(p=0.034)$, with the $\mathrm{AC} / \mathrm{CC}$ genotypes producing greater movement velocity than the AA genotype, and a significant main effect favoring caffeine
( $p<0.001 ; \mathrm{ES}=0.85)$, while we found no significant genotype $\times$ caffeine interaction effect $(p=0.094)$.

\section{Countermovement jump}

For vertical jump height in the CMJ test, we did not find a significant main effect for genotype $(p=0.447)$ or a genotype $\times$ caffeine interaction effect $(p=0.752)$, while there was a significant main effect favoring caffeine ( $p=$ 0.017; ES = 0.15).

\section{Wingate test}

For peak power in the Wingate test, we did not find a significant main effect for genotype $(p=0.998)$ or a genotype $\times$ caffeine interaction effect $(p=0.542)$, while there was a significant main effect favoring caffeine $(p<0.001$; ES $=0.33)$. For mean power in the Wingate test, we did not find a significant main effect for genotype $(p=0.517)$ or a genotype $\times$ caffeine interaction effect $(p=0.583)$, while there was a significant main effect favoring caffeine $(p<0.001 ; \mathrm{ES}=0.35)$. For minimum power in the Wingate test, we did not find a significant main effect for genotype $(p=0.505)$ or a genotype $\times$ caffeine interaction effect $(p=0.396)$, while there was a significant effect favoring caffeine $(p=0.011$; ES $=0.44)$.

\section{Side effects}

In the responses recorded immediately post-exercise, we found a significant difference between the placebo and caffeine conditions only in items "Increased vigor/activeness" and "Perception of improved performance" in the $\mathrm{AC} / \mathrm{CC}$ genotypes (Table 3 ). In the responses 24-h after capsule ingestion, we did not find any significant differences in the incidence of side effects between the placebo and caffeine conditions.

\section{Assessment of blinding - AA genotype}

Before starting the exercise session, in the placebo and caffeine conditions, respectively, $62 \%$ and $54 \%$ of the participants with the AA genotype correctly guessed the treatment identity beyond chance. After exercise, in the placebo and caffeine conditions, respectively, $85 \%$ and $69 \%$ of the participants with the AA genotype correctly guessed the treatment identity beyond chance.

Table 1 Characteristics of the participants

\begin{tabular}{|c|c|c|c|}
\hline Variable & AA group $(n=13)$ & AC/CC group $(n=9)$ & $p$-values from one-way ANOVA \\
\hline Age (years) & $27.0 \pm 5.6$ & $29.8 \pm 3.6$ & 0.205 \\
\hline Body mass (kg) & $78.2 \pm 6.5$ & $80.9 \pm 14.8$ & 0.559 \\
\hline Height (cm) & $182.2 \pm 5.5$ & $183.2 \pm 5.7$ & 0.658 \\
\hline 1RM in the bench press (normalized per body mass) & $1.1 \pm 0.1$ & $1.2 \pm 0.2$ & 0.240 \\
\hline Habitual caffeine intake (mg/day) & $133 \pm 123$ & $117 \pm 68$ & 0.286 \\
\hline
\end{tabular}


Table 2 Effects of caffeine on resistance exercise, jumping, and sprinting performance: results from the two-way, repeated-measures ANOVA

\begin{tabular}{|c|c|c|c|c|c|c|c|c|}
\hline Variable & $\begin{array}{l}\text { AA } \\
\text { genotype } \\
\text { (placebo) }\end{array}$ & $\begin{array}{l}\text { AA } \\
\text { genotype } \\
\text { (caffeine) }\end{array}$ & $\begin{array}{l}\text { AC/CC } \\
\text { genotypes } \\
\text { (placebo) }\end{array}$ & $\begin{array}{l}\text { AC/CC } \\
\text { genotypes } \\
\text { (caffeine) }\end{array}$ & $\begin{array}{l}\text { Main effect } \\
\text { for } \\
\text { genotype } \\
\boldsymbol{p} \text {-value }\end{array}$ & $\begin{array}{l}\text { Main effect } \\
\text { for caffeine } \\
\boldsymbol{p} \text {-value }\end{array}$ & $\begin{array}{l}\text { Genotype } \times \\
\text { caffeine interaction } \\
\text { effect } \\
\boldsymbol{p} \text {-value }\end{array}$ & $\begin{array}{l}\text { Effect size for } \\
\text { condition and its } \\
95 \% \mathrm{Cl}\end{array}$ \\
\hline \multicolumn{9}{|c|}{ Movement velocity and power in the bench press with different loads } \\
\hline $\begin{array}{l}\text { MP at 25\% 1RM } \\
\text { (W) }\end{array}$ & $1892 \pm 299$ & $2012 \pm 325$ & $2152 \pm 501$ & $2279 \pm 517$ & 0.139 & 0.001 & 0.918 & $0.29(0.12,0.46)$ \\
\hline $\begin{array}{l}\text { MV at 25\% 1RM } \\
(\mathrm{m} / \mathrm{s})\end{array}$ & $1.41 \pm 0.12$ & $1.44 \pm 0.14$ & $1.46 \pm 0.16$ & $1.49 \pm 0.15$ & 0.411 & 0.035 & 0.566 & $0.20(0.02,0.39)$ \\
\hline $\begin{array}{l}\mathrm{PP} \text { at } 25 \% 1 \mathrm{RM} \\
\text { (W) }\end{array}$ & $3287 \pm 374$ & $3409 \pm 384$ & $3598 \pm 688$ & $3703 \pm 804$ & 0.215 & 0.033 & 0.868 & $0.20(0.03,0.37)$ \\
\hline $\begin{array}{l}\text { PV at 25\% 1RM } \\
(\mathrm{m} / \mathrm{s})\end{array}$ & $2.21 \pm 0.18$ & $2.27 \pm 0.18$ & $2.31 \pm 0.20$ & $2.35 \pm 0.17$ & 0.244 & 0.008 & 0.806 & $0.26(0.07,0.46)$ \\
\hline $\begin{array}{l}\text { MP at 50\% 1RM } \\
\text { (W) }\end{array}$ & $1182 \pm 145$ & $1217 \pm 154$ & $1279 \pm 214$ & $1333 \pm 249$ & 0.196 & 0.008 & 0.545 & $0.22(0.06,0.39)$ \\
\hline $\begin{array}{l}\text { MV at } 50 \% 1 \mathrm{RM} \\
(\mathrm{m} / \mathrm{s})\end{array}$ & $0.94 \pm 0.08$ & $0.97 \pm 0.08$ & $0.96 \pm 0.11$ & $0.98 \pm 0.10$ & 0.711 & 0.019 & 0.955 & $0.21(0.02,0.42)$ \\
\hline $\begin{array}{l}\text { PP at 50\% 1RM } \\
\text { (W) }\end{array}$ & $1979 \pm 201$ & $2036 \pm 220$ & $2122 \pm 394$ & $2203 \pm 406$ & 0.228 & 0.090 & 0.753 & $0.21(-0.03,0.46)$ \\
\hline $\begin{array}{l}\text { PV at } 50 \% 1 \mathrm{RM} \\
(\mathrm{m} / \mathrm{s})\end{array}$ & $1.41 \pm 0.09$ & $1.43 \pm 0.09$ & $1.44 \pm 0.18$ & $1.48 \pm 0.16$ & 0.468 & 0.031 & 0.489 & $0.23(0.03,0.45)$ \\
\hline $\begin{array}{l}\text { MP at } 75 \% 1 \mathrm{RM} \\
\text { (W) }\end{array}$ & $789 \pm 144$ & $838 \pm 151$ & $849 \pm 148$ & $928 \pm 198$ & 0.281 & $<0.001$ & 0.229 & $0.36(0.19,0.56)$ \\
\hline $\begin{array}{l}\text { MV at } 75 \% 1 \mathrm{RM} \\
(\mathrm{m} / \mathrm{s})\end{array}$ & $0.56 \pm 0.07$ & $0.60 \pm 0.07$ & $0.58 \pm 0.10$ & $0.63 \pm 0.10$ & 0.618 & $<0.001$ & 0.514 & $0.48(0.27,0.72)$ \\
\hline $\begin{array}{l}\mathrm{PP} \text { at } 75 \% 1 \mathrm{RM} \\
\text { (W) }\end{array}$ & $1210 \pm 238$ & $1289 \pm 233$ & $1369 \pm 207$ & $1453 \pm 293$ & 0.128 & 0.007 & 0.940 & $0.31(0.10,0.54)$ \\
\hline $\begin{array}{l}\mathrm{PV} \text { at } 75 \% 1 \mathrm{RM} \\
(\mathrm{m} / \mathrm{s})\end{array}$ & $0.80 \pm 0.12$ & $0.88 \pm 0.09$ & $0.86 \pm 0.17$ & $0.91 \pm 0.17$ & 0.433 & $<0.001$ & 0.243 & $0.50(0.26,0.77)$ \\
\hline $\begin{array}{l}\text { MP at } 90 \% 1 \mathrm{RM} \\
\text { (W) }\end{array}$ & $501 \pm 128$ & $582 \pm 132$ & $588 \pm 109$ & $675 \pm 143$ & 0.103 & $<0.001$ & 0.850 & $0.61(0.31,0.93)$ \\
\hline $\begin{array}{l}\text { MV at } 90 \% 1 \mathrm{RM} \\
(\mathrm{m} / \mathrm{s})\end{array}$ & $0.33 \pm 0.06$ & $0.38 \pm 0.07$ & $0.38 \pm 0.12$ & $0.43 \pm 0.09$ & 0.182 & $<0.001$ & 0.909 & $0.57(0.28,0.89)$ \\
\hline $\begin{array}{l}\text { PP at } 90 \% 1 \mathrm{RM} \\
\text { (W) }\end{array}$ & $821 \pm 225$ & $970 \pm 231$ & $994 \pm 301$ & $1165 \pm 308$ & 0.099 & $<0.001$ & 0.789 & $0.57(0.25,0.91)$ \\
\hline $\begin{array}{l}\text { PV at } 90 \% 1 \mathrm{RM} \\
(\mathrm{m} / \mathrm{s})\end{array}$ & $0.50 \pm 0,09$ & $0.59 \pm 0.11$ & $0.59 \pm 0.18$ & $0.67 \pm 0.13$ & 0.117 & $<0.001$ & 0.966 & $0.59(0.27,0.95)$ \\
\hline \multicolumn{9}{|l|}{ Muscle endurance test } \\
\hline $\begin{array}{l}\text { Maximum } \\
\text { repetitions at } \\
85 \% 1 \mathrm{RM}\end{array}$ & $6.8 \pm 2.3$ & $8.2 \pm 2.2$ & $7.8 \pm 2.4$ & $8.8 \pm 2.2$ & 0.397 & $<0.001$ & 0.454 & $0.53(0.27,0.81)$ \\
\hline $\begin{array}{l}\text { MP matched for } \\
\text { repetitions }(\mathrm{W})\end{array}$ & $376 \pm 86$ & $449 \pm 96$ & $476 \pm 122$ & $531 \pm 159$ & 0.074 & $<0.001$ & 0.406 & $0.53(0.31,0.79)$ \\
\hline $\begin{array}{l}\text { MV matched for } \\
\text { repetitions (m/ } \\
\text { s) }\end{array}$ & $0.25 \pm 0.04$ & $0.30 \pm 0.04$ & $0.30 \pm 0.05$ & $0.33 \pm 0.04$ & 0.034 & $<0.001$ & 0.094 & $0.85(0.50,1.25)$ \\
\hline $\begin{array}{l}\text { PP matched for } \\
\text { repetitions (W) }\end{array}$ & $607 \pm 178$ & $674 \pm 187$ & $741 \pm 297$ & $808 \pm 300$ & 0.201 & $<0.001$ & 0.994 & $0.27(0.14,0.41)$ \\
\hline $\begin{array}{l}\text { PV matched for } \\
\text { repetitions (m/ } \\
\text { s) }\end{array}$ & $0.38 \pm 0.06$ & $0.43 \pm 0.05$ & $0.44 \pm 0.09$ & $0.48 \pm 0.08$ & 0.108 & $<0.001$ & 0.198 & $0.51(0.28,0.77)$ \\
\hline \multicolumn{9}{|l|}{ CMJ } \\
\hline $\begin{array}{l}\text { CMJ vertical } \\
\text { jump height } \\
(\mathrm{cm})\end{array}$ & $34.8 \pm 6.2$ & $35.6 \pm 5.9$ & $36.6 \pm 5.2$ & $37.6 \pm 5.4$ & 0.447 & 0.017 & 0.752 & $0.15(0.03,0.28)$ \\
\hline
\end{tabular}


Table 2 Effects of caffeine on resistance exercise, jumping, and sprinting performance: results from the two-way, repeated-measures ANOVA (Continued)

\begin{tabular}{|c|c|c|c|c|c|c|c|c|}
\hline Variable & $\begin{array}{l}\text { AA } \\
\text { genotype } \\
\text { (placebo) }\end{array}$ & $\begin{array}{l}\text { AA } \\
\text { genotype } \\
\text { (caffeine) }\end{array}$ & $\begin{array}{l}\text { AC/CC } \\
\text { genotypes } \\
\text { (placebo) }\end{array}$ & $\begin{array}{l}\text { AC/CC } \\
\text { genotypes } \\
\text { (caffeine) }\end{array}$ & $\begin{array}{l}\text { Main effect } \\
\text { for } \\
\text { genotype } \\
\boldsymbol{p} \text {-value }\end{array}$ & $\begin{array}{l}\text { Main effect } \\
\text { for caffeine } \\
\boldsymbol{p} \text {-value }\end{array}$ & $\begin{array}{l}\text { Genotype } \times \\
\text { caffeine interaction } \\
\text { effect } \\
\boldsymbol{p} \text {-value }\end{array}$ & $\begin{array}{l}\text { Effect size for } \\
\text { condition and its } \\
95 \% \mathrm{Cl}\end{array}$ \\
\hline \multicolumn{9}{|l|}{ Wingate } \\
\hline $\begin{array}{l}\text { PP in the } \\
\text { Wingate test } \\
\text { (W) }\end{array}$ & $874 \pm 208$ & $943 \pm 197$ & $864 \pm 273$ & $954 \pm 260$ & 0.998 & $<0.001$ & 0.542 & $0.33(0.16,0.52)$ \\
\hline $\begin{array}{l}\text { MP in the } \\
\text { Wingate test } \\
\text { (W) }\end{array}$ & $583 \pm 77$ & $614 \pm 67$ & $606 \pm 120$ & $646 \pm 132$ & 0.517 & $<0.001$ & 0.583 & $0.35(0.20,0.52)$ \\
\hline $\begin{array}{l}\text { MinP in the } \\
\text { Wingate test } \\
\text { (Watts) }\end{array}$ & $338 \pm 108$ & $372 \pm 79$ & $350 \pm 109$ & $414 \pm 114$ & 0.505 & 0.011 & 0.396 & $0.44(0.09,0.81)$ \\
\hline
\end{tabular}

$M P$ mean power, $M V$ mean velocity, $P P$ peak power, $P V$ peak velocity, $1 R M$ one repetition maximum, MinP minimum power, $C M J$ countermovement jump, $C I$ confidence interval

\section{Assessment of blinding - AC/CC genotypes}

Before starting the exercise session, in both the placebo and caffeine conditions, $55 \%$ of the participants with the $\mathrm{AC} / \mathrm{CC}$ genotypes correctly guessed the treatment identity beyond chance. After exercise, in the placebo and caffeine conditions, respectively, $44 \%$ and $78 \%$ of the participants with the $\mathrm{AC} / \mathrm{CC}$ genotypes correctly guessed the treatment identity beyond chance, respectively.

\section{Discussion}

The results of the present study demonstrate that the acute ingestion of a moderate dose of caffeine $(3 \mathrm{mg} / \mathrm{kg})$ may produce significant improvements in: (a) movement velocity and power output in the bench press using loads ranging from 25 to $90 \%$ of $1 \mathrm{RM}$; (b) maximum number of repetitions performed to momentary muscle failure in the bench press exercise, as well as the average quality (i.e., higher movement velocity and power output) of the performed repetitions; (c) vertical jump height; and (d) peak, mean, and minimum power in the 30-s Wingate test. No significant differences in the effects of caffeine were found between the individuals with the AA genotype and the individuals with the AC/CC genotypes in any of the performance tests used in the present study.

Table 3 Perceived side effects based on questionnaires completed immediately after the testing session and the following morning

\begin{tabular}{|c|c|c|c|c|}
\hline Variable & AA group - placebo & AA group - caffeine & AC/CC group - placebo & $\overline{\text { AC/CC group - caffeine }}$ \\
\hline \multicolumn{5}{|c|}{ Immediately after testing session } \\
\hline Muscle soreness & $46 \%$ & $23 \%$ & $0 \%$ & $0 \%$ \\
\hline Increased urine production & $0 \%$ & $23 \%$ & $0 \%$ & $11 \%$ \\
\hline Tachycardia and heart palpitations & $8 \%$ & $8 \%$ & $0 \%$ & $0 \%$ \\
\hline Increased anxiety & $0 \%$ & $23 \%$ & $0 \%$ & $0 \%$ \\
\hline Headache & $8 \%$ & $8 \%$ & $11 \%$ & $11 \%$ \\
\hline Abdominal/gut discomfort & $0 \%$ & $0 \%$ & $0 \%$ & $0 \%$ \\
\hline Increased vigor/activeness & $23 \%$ & $62 \%$ & $0 \%{ }^{\mathrm{a}}$ & $67 \%^{\mathrm{a}}$ \\
\hline Perception of improved performance & $15 \%$ & $62 \%$ & $11 \%^{\mathrm{a}}$ & $100 \%{ }^{\mathrm{a}}$ \\
\hline \multicolumn{5}{|c|}{ The following morning } \\
\hline Muscle soreness & $23 \%$ & $8 \%$ & $0 \%$ & $22 \%$ \\
\hline Increased urine production & $8 \%$ & $0 \%$ & $0 \%$ & $11 \%$ \\
\hline Tachycardia and heart palpitations & $0 \%$ & $0 \%$ & $0 \%$ & $0 \%$ \\
\hline Increased anxiety & $0 \%$ & $0 \%$ & $0 \%$ & $0 \%$ \\
\hline Headache & $8 \%$ & $8 \%$ & $22 \%$ & $0 \%$ \\
\hline Abdominal/gut discomfort & $0 \%$ & $0 \%$ & $0 \%$ & $0 \%$ \\
\hline Insomnia & $8 \%$ & $0 \%$ & $0 \%$ & $11 \%$ \\
\hline Increased vigor/activeness & $0 \%$ & $0 \%$ & $0 \%$ & $33 \%$ \\
\hline
\end{tabular}

${ }^{\mathrm{a}}$ Significant difference between the placebo and caffeine conditions within a group 


\section{Effects of caffeine on exercise performance}

In the bench press exercise, caffeine ingestion enhanced peak and mean velocity and consequently, mean and peak power, when exercising with low, moderate, and high loads. These results are generally in line with previous findings [18, 20,22]. One of the early studies [18] conducted on this topic reported that high doses of caffeine $(9 \mathrm{mg} / \mathrm{kg})$ are required for acute increases in movement velocity when exercising with very high loads (90\% 1RM). However, our results suggest that a dose of $3 \mathrm{mg} /$ $\mathrm{kg}$ is effective for enhancing velocity across a wide range of external loads, suggesting that very high doses might not be needed. This is especially relevant to highlight as the ESs in our study are very similar to those reported for the bench press exercise by Pallarés et al. [18].

A recent meta-analysis found that caffeine ingestion enhances mean and peak movement velocity in resistance exercise [27]. The researchers also noted that the effects of caffeine on mean velocity $(E S=0.80)$ were higher than those for peak velocity $(E S=0.41)$ [27]. However, the studies included in that meta-analysis assessed either mean or peak velocity; that is, no studies included in the meta-analysis measured both outcomes in the same group of participants [27]. In the present study, we found that the ESs were very similar for both mean and peak velocity, and this was a constant finding across all the employed loads (i.e., 25 to $90 \%$ of 1RM).

The muscle endurance test used in this study further confirmed that caffeine ingestion is ergogenic for this fitness component in resistance-trained men. This study adds to the body of evidence showing improvements in muscle endurance following caffeine ingestion [28-32]. However, a more novel finding is that caffeine is ergogenic for power and velocity outputs when the number of repetitions between the caffeine and placebo conditions is matched. Specifically, when matching the number of repetitions between conditions, we found that the effects of caffeine, as compared to placebo, amounted to 0.27 for peak power, 0.51 for peak velocity, 0.53 for mean power, and 0.85 for mean velocity. Several studies that explored the effects of caffeine on muscle endurance did not find a difference in the number of performed repetitions between the caffeine and placebo conditions [13, 33, 34]. However, as we demonstrated in the present study, even with an equal number of repetitions between conditions, caffeine might have still produced considerable improvements in the quality of the performed repetitions, that is, greater movement velocity and consequently, greater power output (which was not tested in the aforementioned studies). As compared to placebo, caffeine ingestion most commonly produced moderate improvements in the number of performed repetitions (generally one to three additional repetitions) $[28,31]$. We propose that in some contexts, improvements in the overall quality of the performed repetitions may be more important for training adaptations than simply performing a greater number of repetitions. This hypothesis is in line with recent findings that training at a velocity loss of $20 \%$ produced greater improvement in CMJ performance than training at a $40 \%$ velocity loss [35]. Improvements in squat strength were similar for both training conditions, even though the group that trained with a velocity loss of $20 \%$ performed $40 \%$ fewer repetitions.

Caffeine ingestion resulted in increased vertical jump height in the CMJ. The ES magnitude of 0.15 observed in this study is very similar to the pooled ES of 0.17 reported in a recent meta-analysis of 10 studies [36]. This result, therefore, confirms that caffeine ingestion may have a relatively small performance-enhancing effect on vertical jump height [36-38]. The acute improvement in vertical jump height following caffeine ingestion is comparable to the improvement in jump height found as a result of 4 weeks of plyometric training [39, 40]. Even though the improvement in performance was relatively small (approximately $1 \mathrm{~cm}$ ), it might still be practically meaningful in sports where jump height directly impacts athletic outcomes.

In the Wingate test, we found a significant ergogenic effect of caffeine on peak, mean, and minimum power. These results are in line with the findings of a recent meta-analysis that reported ergogenic effects of caffeine on mean and peak power in the ES magnitude of 0.18 and 0.27 , respectively [41]. Of the 16 studies included in the meta-analysis [41], 12 studies used caffeine doses of 5 or $6 \mathrm{mg} / \mathrm{kg}$. Therefore, it could be argued that the findings of the meta-analysis should primarily be generalized to these doses of caffeine. In the present study, we found that even a lower dose of caffeine (namely, $3 \mathrm{mg} /$ $\mathrm{kg}$ ), increases performance in this test and that the ES is very similar to that reported by studies using higher caffeine doses [41].

\section{The influence of the CYP1A2 genotype}

We did not find significant genotype $x$ caffeine interaction effects in any of the analyzed performance variables. It might be that the effects of caffeine ingestion are similar between different CYP1A2 genotypes, at least for the performance tests used in the present study. The results reported herein are generally in line with the current body of evidence. Two studies $[11,12]$ that explored the effects of caffeine on jumping and Wingate test performance reported similar improvements in these outcomes following the ingestion of $3 \mathrm{mg} / \mathrm{kg}$ of caffeine in groups of participants with the $\mathrm{AA}$ and $\mathrm{AC} / \mathrm{CC}$ genotypes. However, a recent study [13] that used a resistance exercise protocol, found that caffeine is ergogenic only for individuals with the AA genotype. On average, 
individuals with the AA genotype were able to complete one more repetition with the consumption of caffeine, as compared to placebo, whereas the number of repetitions was the same in the placebo and caffeine conditions among those with the $\mathrm{AC} / \mathrm{CC}$ genotypes. The main methodological difference between the current studies exploring this topic was the dose of caffeine administered to the participants. Specifically, we and two other studies that reported similar results utilized $3 \mathrm{mg} / \mathrm{kg}$ of caffeine. We opted to utilize a lower dose of caffeine as higher doses of caffeine do not seem to produce greater increases in performance [28]. In the study by Rahimi [13], the dose was considerably higher (i.e., $6 \mathrm{mg} / \mathrm{kg}$ ). It might be that the differences in responses between genotypes become apparent only at higher doses of caffeine. Future dose-response studies might consider exploring this hypothesis further. The effectiveness of the blinding was not explored by Rahimi [13] thus limiting the comparison of the results in this aspect of the study design.

Even though Rahimi [13] reported that caffeine ingestion is ergogenic for AA but not $\mathrm{AC} / \mathrm{CC}$ genotypes in resistance exercise, the main outcome of that study was the number of performed repetitions in 4 different resistance exercises with $85 \% 1 \mathrm{RM}$, which can be considered as a somewhat crude test of performance. As mentioned previously, we demonstrated that even when matched for the number of repetitions, caffeine, as compared to placebo, increases the average movement velocity and power output of the performed repetitions (ES range $=0.27$ to 0.85 ). Therefore, even though Rahimi [13] reported that in the $\mathrm{AC} / \mathrm{CC}$ genotypes the total number of repetitions was the same following the ingestion of caffeine and placebo, caffeine might have still enhanced the average velocity and power of these repetitions. We would suggest that future research in this area explores both the quality and quantity of the performed repetitions, to provide a more comprehensive assessment of possible effects of caffeine.

\section{Strengths and limitations}

Some of the key strengths of this study are: (a) the standardization of testing conditions, including nutritional intake, physical activity, and the time of day at which the testing is conducted; (b) the inclusion of trained individuals as study participants; (c) a broad range of exercise performance variables that were assessed as outcomes; (d) assessment of performance across a wide-range of loads in the bench press exercise and both quantity and quality of repetitions, when examining muscle endurance as the outcome variable.

There are several potential limitations of this study that need to be acknowledged. First, due to the low number of individuals with the CC genotype, we combined the $\mathrm{AC}$ and $\mathrm{CC}$ genotypes into one group. This is fairly common in this line of research, as the number of individuals with the CC genotype in the population is suggested to be $\sim 10 \%$ [9]. To get around 10 to 12 participants with the CC genotype a study would need to screen from 100 to 120 potential study participants. However, despite the fact this is a common practice, it could have confounded findings, as the effects of caffeine might not be uniform between individuals with the AC vs. CC genotype [10, 42]. In the current study, we could not test this further, because the number of individuals with the CC genotype was $n=2$. Of note, the exclusion of these two participants from the analysis did not alter the study results.

The second limitation is related to the efficacy of blinding [24]. Previous research has established that correct supplement identification may impact the outcomes of a given exercise test and, therefore, bias the results. In the present study, around $50-60 \%$ of the participants were able to correctly identify the placebo and caffeine condition beyond random chance in the pre-exercise assessment. In the post-exercise assessment, this percentage generally stayed the same or slightly increased. We believe that the pre-exercise responses are of greater importance, given that the improvements during the testing session (or lack thereof) may influence the postexercise responses. Tallis and colleagues [43] tested their participants in four conditions: (1) "told caffeine, given caffeine"; (2) "told caffeine, given placebo"; (3) "told placebo, given placebo"; and (4) "told placebo, given caffeine". Equal improvements were found on both occasions when the participants indeed ingested caffeine (i.e., "told caffeine, given caffeine" and "told placebo, given caffeine" conditions), thus suggesting that this limitation of our study might not have greatly affected our findings.

\section{Conclusions}

This study found that caffeine is acutely ergogenic for movement velocity, power output, and muscle endurance in resistance exercise, vertical jump height, and peak, mean, and minimum power in a Wingate test. These performance-enhancing effects were observed following the ingestion of using a moderate dose of caffeine $(3 \mathrm{mg} / \mathrm{kg})$, which resulted in minimal side effects. The comparisons of the effects of caffeine on exercise performance between individuals with the AA genotype and $\mathrm{AC} / \mathrm{CC}$ genotypes found no significant differences.

\section{Abbreviations}

1RM: One repetition maximum; ANOVA: Analysis of variance; Cl: Confidence interval; CMJ: Countermovement jump; ES: Effect size; PAR-Q: Physical

Activity Readiness Questionnaire; PCR: Polymerase chain reaction

\section{Acknowledgements}

The authors would like to thank DNAFit Life Sciences for providing the genotype analysis. 


\section{Authors' contributions}

$J G$, DJB, and ZP conceived and designed the study. JG performed the experiments, analyzed the data, and wrote the first draft. ZP, DJB, CP, BJS, and PM critically revised the manuscript. All authors read and approved the final manuscript.

\section{Funding}

None.

\section{Availability of data and materials}

The datasets used and/or analyzed during the current study are available from the corresponding author on reasonable request.

\section{Ethics approval and consent to participate}

The study protocol was approved by the Victoria University Human Research Ethics Committee (HRE19-019). The research was performed in accordance with the Declaration of Helsinki.

\section{Consent for publication}

Not applicable.

\section{Competing interests}

The authors declare that they have no competing interests. Craig Pickering is a former employee of DNAFit Ltd., a genetic testing company. He received no financial incentives for the preparation of this manuscript.

\section{Author details}

${ }^{1}$ Institute for Health and Sport (IHES), Victoria University, Melbourne, Australia. ${ }^{2}$ Institute of Coaching and Performance, School of Sport and Wellbeing, University of Central Lancashire, Fylde Road, Preston PR1 2HE, UK. ${ }^{3}$ School of Medical and Health Sciences, Edith Cowan University, Joondalup, Australia. ${ }^{4}$ Department of Health Sciences, Lehman College, Bronx, USA. ${ }^{5}$ Faculty of Kinesiology, University of Zagreb, Zagreb, Croatia.

\section{Received: 29 January 2020 Accepted: 30 March 2020}

\section{Published online: 15 April 2020}

\section{References}

1. Graham TE. Caffeine and exercise: metabolism, endurance and performance. Sports Med. 2001;31:785-807.

2. McLellan TM, Caldwell JA, Lieberman HR. A review of caffeine's effects on cognitive, physical and occupational performance. Neurosci Biobehav Rev. 2016;71:294-312

3. Grgic J, Grgic I, Pickering C, Schoenfeld BJ, Bishop DJ, Pedisic Z. Wake up and smell the coffee: caffeine supplementation and exercise performance - an umbrella review of 21 published meta-analyses. $\mathrm{Br}$ Sports Med. 2019. https://doi.org/10.1136/bjsports-2018-100278.

4. Pickering $C$, Kiely J. Are the current guidelines on caffeine use in sport optimal for everyone? Inter-individual variation in caffeine ergogenicity, and a move towards personalised sports nutrition. Sports Med. 2018:48:7-16.

5. Grgic J, Mikulic P. Caffeine ingestion acutely enhances muscular strength and power but not muscular endurance in resistance-trained men. Eur J Sport Sci. 2017;17:1029-36.

6. Womack CJ, Saunders MJ, Bechtel MK, Bolton DJ, Martin M, Luden ND, Dunham W, Hancock M. The influence of a CYP1A2 polymorphism on the ergogenic effects of caffeine. J Int Soc Sports Nutr. 2012;9:7.

7. $\quad$ Pickering C, Grgic J. Caffeine and exercise: what next? Sports Med. 2019;49: 1007-30.

8. Gu L, Gonzalez FJ, Kalow W, Tang BK. Biotransformation of caffeine, paraxanthine, theobromine and theophylline by cDNA-expressed human CYP1A2 and CYP2E1. Pharmacogenetics. 1992;2:73-7.

9. Sachse C, Brockmöller J, Bauer S, Roots I. Functional significance of a C $\rightarrow$ a polymorphism in intron 1 of the cytochrome P450 CYP1A2 gene tested with caffeine. Br J Clin Pharmacol. 1999:47:445-9.

10. Guest N, Corey P, Vescovi J, El-Sohemy A. Caffeine, CYP1A2 genotype, and endurance performance in athletes. Med Sci Sports Exerc. 2018;50:1570-8.

11. Puente C, Abián-Vicén J, Del Coso J, Lara B, Salinero JJ. The CYP1A2 $-163 C>$ a polymorphism does not alter the effects of caffeine on basketball performance. PLoS One. 2018;113:e0195943.

12. Salinero Jل, Lara B, Ruiz-Vicente D, Areces F, Puente-Torres C, Gallo-Salazar C, Pascual T, Del Coso J. CYP1A2 genotype variations do not modify the benefits and drawbacks of caffeine during exercise: a pilot study. Nutrients 2017:9:E269

13. Rahimi R. The effect of CYP1A2 genotype on the ergogenic properties of caffeine during resistance exercise: a randomized, double-blind, placebocontrolled, crossover study. Ir J Med Sci. 2019;188:337-45.

14. Grgic J, Lazinica B, Garofolini A, Schoenfeld BJ, Saner NJ, Mikulic P. The effects of time of day-specific resistance training on adaptations in skeletal muscle hypertrophy and muscle strength: a systematic review and metaanalysis. Chronobiol Int. 2019;36:449-60.

15. Bühler E, Lachenmeier DW, Schlegel K. Winkler G development of a tool to assess the caffeine intake among teenagers and young adults. Ernährungs Umschau. 2014;61:58-63.

16. Grgic J, Pickering C, Bishop DJ, Del Coso J, Schoenfeld BJ, Tinsley GM, Pedisic Z. ADORA2A C Allele Carriers Exhibit Ergogenic Responses to Caffeine Supplementation. Nutrients. 2020;12:E741.

17. González-Badillo JJ, Sánchez-Medina L. Movement velocity as a measure of loading intensity in resistance training. Int J Sports Med. 2010;31:347-52.

18. Pallarés JG, Fernández-Elías VE, Ortega JF, Muñoz G, Muñoz-Guerra J, MoraRodríguez R. Neuromuscular responses to incremental caffeine doses: performance and side effects. Med Sci Sports Exerc. 2013;45:2184-92.

19. Orange ST, Metcalfe JW, Marshall P, Vince RV, Madden LA, Liefeith A. Testretest reliability of a commercial linear position transducer (GymAware PowerTool) to measure velocity and power in the back squat and bench press. J Strength Cond Res. 2020;34:728-37.

20. Venier S, Grgic J, Mikulic P. Acute enhancement of jump performance, muscle strength, and power in resistance-trained men after consumption of caffeinated chewing gum. Int J Sports Physiol Perform. 2019;14:1415-21.

21. Frikha M, Chaâri N, Mezghanni N, Souissi N. Influence of warm-up duration and recovery interval prior to exercise on anaerobic performance. Biol Sport 2016:33:361-6.

22. Venier S, Grgic J, Mikulic P. Caffeinated gel ingestion enhances jump performance, muscle strength, and power in trained men. Nutrients. 2019; 11:E937.

23. Diaz-Lara FJ, Del Coso J, García JM, Portillo LJ, Areces F, Abián-Vicén J. Caffeine improves muscular performance in elite Brazilian Jiu-jitsu athletes. Eur J Sport Sci. 2016:16:1079-86.

24. Saunders B, de Oliveira LF, da Silva RP, de Salles PV, Gonçalves LS, Yamaguchi G, Mutti T, Maciel E, Roschel H, Artioli GG, Gualano B. Placebo in sports nutrition: a proof-of-principle study involving caffeine supplementation. Scand J Med Sci Sports. 2017;27:1240-7.

25. Pickering C, Kiely J, Suraci B, Collins D. The magnitude of Yo-Yo test improvements following an aerobic training intervention are associated with total genotype score. PLoS One. 2018:13:e0207597.

26. Bang $\mathrm{H}, \mathrm{Ni} \mathrm{L}$, Davis CE. Assessment of blinding in clinical trials. Control Clin Trials. 2004:25:143-56

27. Raya-González J, Rendo-Urteaga T, Domínguez R, Castillo D, RodríguezFernández A, Grgic J. Acute effects of caffeine supplementation on movement velocity in resistance exercise: a systematic review and metaanalysis. Sports Med. 2019. https://doi.org/10.1007/s40279-019-01211-9.

28. Grgic J, Sabol F, Venier S, Mikulic I, Bratkovic N, Schoenfeld BJ, Pickering C, Bishop DJ, Pedisic Z, Mikulic P. What dose of caffeine to use: acute effects of 3 doses of caffeine on muscle endurance and strength. Int J Sports Physiol Perform. 2019. https://doi.org/10.1123/ijspp.2019-0433.

29. Polito MD, Souza DB, Casonatto J, Farinatti P. Acute effect of caffeine consumption on isotonic muscular strength and endurance: a systematic review and meta-analysis. Sci Sports. 2016;31:119-28.

30. Cook C, Beaven CM, Kilduff LP, Drawer S. Acute caffeine ingestion's increase of voluntarily chosen resistance-training load after limited sleep. Int I Sport Nutr Exerc Metab. 2012;22:157-64.

31. Warren GL, Park ND, Maresca RD, McKibans KI, Millard-Stafford ML. Effect of caffeine ingestion on muscular strength and endurance: a meta-analysis. Med Sci Sports Exerc. 2010:42:1375-87.

32. Grgic J, Mikulic P, Schoenfeld BJ, Bishop DJ, Pedisic Z. The influence of caffeine supplementation on resistance exercise: a review. Sports Med. 2019; 49:17-30

33. Woolf K, Bidwell WK, Carlson AG. Effect of caffeine as an ergogenic aid during anaerobic exercise performance in caffeine naïve collegiate football players. J Strength Cond Res. 2009:23:1363-9.

34. Goldstein E, Jacobs PL, Whitehurst M, Penhollow T, Antonio J. Caffeine enhances upper body strength in resistance-trained women. J Int Soc Sports Nutr. 2010;7:18 
35. Pareja-Blanco F, Rodríguez-Rosell D, Sánchez-Medina L, Sanchis-Moysi J, Dorado C, Mora-Custodio R, Yáñez-García JM, Morales-Alamo D, PérezSuárez I, Calbet JAL, González-Badillo JJ. Effects of velocity loss during resistance training on athletic performance, strength gains and muscle adaptations. Scand J Med Sci Sports. 2017;27:724-35.

36. Grgic J, Trexler ET, Lazinica B, Pedisic Z. Effects of caffeine intake on muscle strength and power: a systematic review and meta-analysis. J Int Soc Sports Nutr. 2018;15:11.

37. Bloms LP, Fitzgerald JS, Short MW, Whitehead JR. The effects of caffeine on vertical jump height and execution in collegiate athletes. J Strength Cond Res. 2016;30:1855-61.

38. Sabol F, Grgic J, Mikulic P. The effects of 3 different doses of caffeine on jumping and throwing performance: a randomized, double-blind, crossover study. Int J Sports Physiol Perform. 2019;14:1170-7.

39. Markovic G. Does plyometric training improve vertical jump height? A meta-analytical review. Br J Sports Med. 2007;41:349-55.

40. Chimera NJ, Swanik KA, Swanik CB, Straub SJ. Effects of plyometric training on muscle-activation strategies and performance in female athletes. J Athl Train. 2004;39:24-31.

41. Grgic J. Caffeine ingestion enhances Wingate performance: a meta-analysis. Eur J Sport Sci. 2018;18:219-25.

42. Koonrungsesomboon N, Khatsri R, Wongchompoo P, Teekachunhatean S. The impact of genetic polymorphisms on CYP1A2 activity in humans: a systematic review and meta-analysis. Pharmacogenomics J. 2018;18:760-8,

43. Tallis J, Muhammad B, Islam M, Duncan MJ. Placebo effects of caffeine on maximal voluntary concentric force of the knee flexors and extensors. Muscle Nerve. 2016;54:479-86.

\section{Publisher's Note}

Springer Nature remains neutral with regard to jurisdictional claims in published maps and institutional affiliations.

Ready to submit your research? Choose BMC and benefit from:

- fast, convenient online submission

- thorough peer review by experienced researchers in your field

- rapid publication on acceptance

- support for research data, including large and complex data types

- gold Open Access which fosters wider collaboration and increased citations

- maximum visibility for your research: over $100 \mathrm{M}$ website views per year

At $\mathrm{BMC}$, research is always in progress.

Learn more biomedcentral.com/submissions 